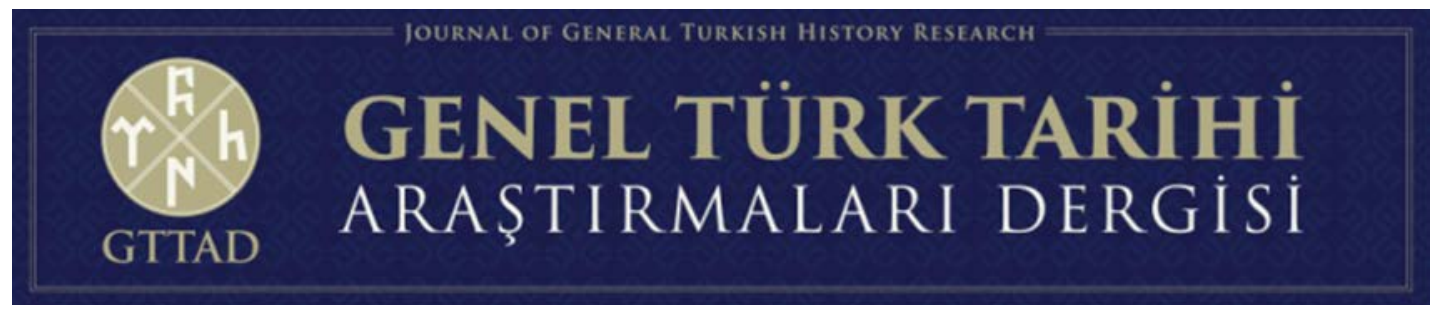

Cilt/Volume 3, Sayı/Issue 6, Temmuz/July 2021, ss. 553-558.

Geliş Tarihi-Received Date: 18.12.2020 Kabul Tarihi-Accepted Date: 16.04.2021

ÇEVIRI MAKALE - TRANSLATION ARTICLE

TOKTAMIŞ VE TIMUR'UN MÜCADELESİ ZAMANINDA VEBA*

ILNUR M. MIRGALEEV**

çev. ERHAN KARAOĞLAN ${ }^{* * *}$

ÖZ

Moğolların yayılmasından sonra Cuci Ulusu Karadeniz'in kuzeyinde hâkimiyetini tesis ederek Altın Orda Devleti'ni vücuda getirmiş̧ti. Devlet, buradaki mevcudiyetinin ardından siyasi, kültürel, ekonomik her alanda aktif ve önemli bir otorite haline gelmiştir. Sürekli devam eden fetihlerle Avrasya'daki hâkimiyetini genişleten Altın Orda hanları, Rus ve Litvan prensliklerini kâmilen boyunduruk altına almışlar, İlhanlılar ile geniş ölçekli siyasi mücadeleler yaşamışlardır. Diğer yandan da Memlûk Devleti ile dostluk zemininde ilişkiler yürütmüşlerdir. Özbek Han'dan sonra giderek otorite kayıpları yaşayan Altın Orda Devleti'nin bu vaziyetine paralel olarak güçlü rakipler ortaya çıkmaya başlamıştır. Aynı zamanda hanlar arasındaki taht mücadeleleri ve bazı Nogay beylerinin kendi başlarına buyruk davranmaları bu vaziyeti daha da hızlandırmıştır. Toktamış Han iktidarı zamanında ise Altın Orda Devleti yeniden toparlanmaya başlamış, Rus knezliklerinin Tatar hanlarına olan bağlılıkları yeniden güçlendirilmeye çalışılmıştı. Bir yandan Cuci Ulusu bu gayretler içerisine girerken, diğer yandan da Hülegü ve Çağatay uluslarının küllerinde yeni bir devlet inşa eden Emir Timur’un büyüyen askerî kuvveti ve bölgesel çıkarlarıyla karşı karşıya kalmıştı. Nihayetinde ise Toktamış Han ve Emir Timur arasında büyük bir savaş yaşanmıştı. Yaşanan savaşın ardından Altın Orda Devleti, Emir Timur'a bağlı bir devlet haline gelmiş ve sonrasında da aynı iç karışıklıklar devam ederek nihayetinde 1502 yılında tarihin sükût âlemine doğru çekilmiştir.

İşbu çalışmada ise Altın Orda Devleti tarihinde büyük bir öneme sahip olan Toktamış Han ve Emir Timur'un arasındaki mücadelelere değinilerek, Toktamış Han'ın aldığı yenilginin sebepleri üzerinde durulmuştur. Birçok araştırmacı tarafından bu konu ele alınmış ve beraberinde ihtilaflı görüşler ortaya çıkmıştır. Günümüzde modern yöntemlerin gelişmesi ve disiplinler arası çalışmaların artmasıyla beraber yeni bulgulara ulaşılarak farklı görüşler öne sürülmüsşür. Bu türden farklı görüşlerden biri bu çalışmada beyan edilmiştir. Çalışma temel dayanak noktası olarak Orta Çağdaki yaygın salgın hastalıkları ele almaktadır. Bunu yaparken farklı disiplinler arası çalışmalar ile iklimsel değişimler ve bölgedeki insanlar üzerinde vebanın izlerinin toplandığı veriler elde edilmiştir. Ancak bu yöntemin herhangi bir faraziyeye dönüşmemesi için de elde edilen verilerle yazılı kaynaklarda bulunan veriler mukayeseli olarak kullanılmış, daha açık bir cümle ile bir dönem içerisinde bulunan verilerin izleri, en erken anlatısal kaynaklarda aranarak bir mukayeseli araştırma yöntemi kullanılmıştır. Bunun yanı sıra, Altın Orda Devleti'ni kapsayan bugünkü Rusya ve Doğu Avrupa'daki mezar alanlarında salgının izleri aranmıştır. Tıbbî bilimlerden de yararlanılan bu çalışmada Toktamış Han ve Emir Timur arasındaki mücadeleyi etkileyen ana etmenlerden biri olarak salgın hastalıkların olabileceği fikri beyan edilmiş ve Orta çağın en büyük salgınlarından birinin Cuci Ulusunun mülkünde gerçekleştiği görüşü belirtilmiştir. Makalede kullanılan bu yöntem ve izlenen yol haritasıyla beraber Altın Orda Devleti araştırmalarına yeni bir yaklaşım kazandırıldığı söylenebilir.

Anahtar Kelimeler: Altın Orda, Toktamış, Timur, Kara Ölüm, Epidemi.

\footnotetext{
* İlnur, M. MiRGALEEV, “Çuma Vo Vremya Protivostoyaniya Toxtamışa s Timurom”, Epidemi i Prirodnıye Kataklizmı v Zolotoy Orde i Na Sopredelnih Territoriyah (XIII- XVI vv.), (Redaktor: İlnur, M. Mirgaleev), İnstitut İstorii İm. Ş. Mardjani Nauk Respubliki Tatarstan, Kazan 2018, s. $144-149$.

*** Doç. Dr., Mercani Tarih Enstitüsü, E-Posta: dilnur1976@gmail.com.

${ }^{* * *}$ Yüksek Lisans Öğrencisi, Hacettepe Üniversitesi, Sosyal Bilimler Enstitüsü, Tarih Anabilim Dalı, E-Posta: erhankagan@gmail.com, ORCID ID: 0000-00025709-8032
} 


\title{
TOKTAMIŞ VE TIMUR'UN MÜCADELESİ ZAMANINDA VEBA
}

\section{PLAGUE IN THE TIME OF TOKHTAMYSH AND TIMUR'S STRUGGLE}

\begin{abstract}
After the spread of the Mongols, the Cuci Nation established its dominance in the north of the Black Sea, creating the state of the Golden Horde. Here the presence of the state in the aftermath of political, cultural, and economic authority in all areas has become active and important. The Khans of the Golden Horde, which extends the ongoing conquest domination in Eurasia, the Russian principalities under the yoke of their territories, and they got it Latvian extract of the khanate, with large-scale political struggles to have experienced. On the other hand, on the ground of friendship with the Mamluk state relations. After the Uzbek Khan the loss of authority of the Empire Golden Horde increasingly parallel to the situation of living, strong competitors have begun to emerge. At the same time, some struggles for the throne among the Khans Nogai acting in their own right, this situation has accelerated even more. Tokhtamysh Khan's rule in the time of the state of the Golden Horde began to recover, the Russian of Tatar Khan was an attempt to reinforce their commitment to principalities. On the one hand, the Cuci Nation was engaged in these efforts, and on the other hand, the ashes of the Hulegu and Chagatai nations were faced with the growing military force and regional interests of Emir Timur, who had built a new state. In the end, there was a great battle between Tokhtamysh Khan and Timur. After the war, the state of the Golden Horde became a state associated with Emir Timur, and then the same internal turmoil continued, eventually retreating to the world of tranquility of history in 1502.

In this study, the struggles between Tokhtamysh Khan and Emir Timur, which were of great importance in the history of the Golden Horde State, were discussed and the reasons for the defeat of Tokhtamysh Khan were emphasized. This issue has been addressed by many researchers, and with it conflicting opinions have emerged. Today, with the development of modern methods and the increase of Interdisciplinary Studies, new findings have been reached and different opinions have been put forward. In this study, it has been stated opinion one of this kind of different. The study is based on common epidemics in the Middle Ages as a mainstay. While doing this, and the plague on the people of the region through interdisciplinary studies in different climatic changes, the traces of the collected data have been obtained. However, this method for interpreting the data in any assumption based on comparative data obtained with the written sources used, the narrative traces the earliest sources of data in a period with a lighter sentence by searching in a comparative research method was used. Besides traces of the outbreak were searched in burial sites in present-day Russia and Eastern Europe, including the Golden Horde State. In this study, which also used medical sciences, the idea that epidemics could be one of the main factors affecting the struggle between Tokhtamysh Khan and Emir Timur was declared and the opinion that one of the biggest epidemics of the Middle Ages took place on the property of the Cuci Nation was stated. Along with this method used in the article and the road map followed, it can be said that a new approach was given to research the state of the Golden Horde.
\end{abstract}

Keywords: Golden Horde, Tokhtamysh, Timur, The Black Death, Epidemic.

\section{TOKTAMIŞ VE TIMUR'UN MÜCADELESİ ZAMANINDA VEBA}

Toktamış Han'ın siyasi kuvvetini artırması ve Altın Orda Devleti içerisindeki sıkıntılara son vermesi, devletin, uluslararası siyasette yeniden aktif bir rol oynamasında etkili olmuştur. Ancak bu dönemde Çağatay ve Hülegü uluslarının külleri üzerinde yeniden güçlü ve büyük bir devlet inşa eden Timur'un çıkarlarıyla Toktamış'ın politikaları çok çabuk bir şekilde kesişti.

Toktamış'ın Timur ile mücadelesini konu edinen geniş bir literatür söz konusudur. Bu dönemde, Toktamış, Cuci Ulusu içerisinde yapmış olduğu askerî reformlara ${ }^{1}$ ve Timur'a karşı destek bulmuş olduğu müttefiklere rağmen, yine de Timur kadar güçlü değildi. ${ }^{2}$ Neticede gerçekleşen savaş, Orta Çăg'ın en büyük savaşı olarak hâtıralardan silinmedi.

Bilim adamları tarafından yapılan bilimsel çalışmalarla Toktamış'ın yenilgisinin sebepleri ayrı ayrı ele alınarak incelenmiş ve o dönemde sıkça rastlanan salgınların yenilgideki faktörler arasında olduğu belirtilmiştir. Elde edilen epidemolojik verilere ve yayımlanan kaynaklara göre Altın Orda topraklarında dönemin en güçlü salgın hastalıklarından biri olan vebanın gerçekleştiği sonucu ortaya çıkmaktadır. Fakat kaynaklardaki bilgilerin kıtlığı, araştırmacıların konuyu daha detaylı ele almalarına izin vermemektedir. Bununla birlikte, 14. yüzyılın ortalarında,

${ }^{1}$ İ. M. Mirgaleev, Politiçeskaya İstoriya Zolotoy Ordı Perioda Pravleniya Toktamış-Hana, Kazan: Alma-lit, 2003, s. 63-84

2 İ. M. Mirgaleev, "Toktamıș i Timur: Restavratsiya Antimamlyukskoy Koalitsi”, 2. Materialı Vtoroy Mejdunarodnoy Nauçnoy Konferentsi

"Politiçeskaya i Sotsialnaya İstoriya Zolotoy Ordı”, Posviyeşennaya Pamyati M.A. Usmanova, Kazan, 29-30 Marta, 2011, s. 27-32 


\section{ILNUR M. MIIRGALEEV}

Altın Orda topraklarında "kara ölüm” gibi periyodik olarak salgın hastalıkların kaynaklarının ortaya çıktığını rahatlıkla iddia edebiliriz. Hatta Cuci Ulusu'nun geniş topraklarında vebanın doğal kaynaklarının bulunduğunu ve başta Aşağı İtil olmak üzere ülkenin merkez bölgelerinin bu felaketin ana kurbanları olduklarını dile getirebiliriz. Yeni salgınlar da bu dönemde kalıcı olarak ortaya çıkmaya başlamış ve Timur ile Toktamış'ın mücadelesi sırasında yeniden yükselmiştir.

Cuci Ulusu’ndaki hızlı politik değişimler, günümüz araştırmacıları arasında büyük tartışmaları beraberinde getirmektedir. Vebanın kuvvetli yayılımının kronolojideki tutarsızlı̆̆ı, ani ölümleri ya da bir yenilginin ardından gelen hızlı taht değişikliklerini açıklamada zorluklar çıkarmaktadır. Bu türden anormallikleri salgın hastalıklar ve diğer antropojenik olmayan faktörlerle incelemek gerekmektedir.

Bundan dolayı, şüphesiz, yeni bilgilerin kullanımı ve ilgili disiplinlerin yardımıyla yeni bilgiler elde edilebilmektedir. Çağdaş disiplinler arası araştırmaların en popüler olanlarından biri tarihsel olarak geriye dönük iklimsel değişimleri ve bölgedeki insanlar üzerindeki güçlü salgın hastalık bulgularından ortaya çıkarılan verilerdir. Aslında tarihin beyaz lekeleri olarak nitelendirebileceğimiz bu sonuçlara dair Orta Çağ insanının bir tıbbî haritasının çıkarılması mümkün olabilir. Ancak tarihî olayların doğa ilimleri ile mukayeseli bir şekilde ele alınarak incelenmesi hususunda henüz yolun başındayız. Fakat hâlâ bu çalışma metodunda yolun başında olsak da, elde edilen verilerin bu disiplin çerçevesinde nasıl uygulanabileceğine dair bir anlayış bulunmamaktadır.

Doğa bilimlerinin yöntemlerini tarihsel araştırmalara konu etmenin en büyük tehlikelerinden biri bilim insanlarının çeşitli ihtilafları içerisinde barındıran hipotezler ortaya çıkarmasıdır. Bu tartışmaların önüne geçebilmek adına elde edilen verilerin en erken dönemlerdeki anlatısal kaynakları ile doğa bilimleri arasında ilişki kurmak gerekmektedir. Nihayetinde böyle çalışmalar, tarih ilminde ortaya çıkan metodolojik krizlerin en kısa sürede çözülmesinde yardımcı olacaktır. Bununla birlikte, uzmanların tarih ilmi bünyesinde doğa bilimlerine mukabil dogmatik yaklaşımları, elde edilen verilerin sansasyonel boyutlara ulaşmasına neden olabilmektedir.

Y. Krayze'nin araştırma grubunun makaleleri, benzer çalışmaların açıklayıcı örnekleri olabilir. ${ }^{3}$ Almanya, İngiltere ve Rusya (Bulgar)'nın belirtilen bölgelerinde bulunan mezar kalıntılarında Orta Çağ kara vebası ile ilgili ilk çalışmalar bu araştırmada yürütüldü. Konu ile ilgili bulguların eksikliğinde Rusya'nın dört bir tarafında bulunan mezar kalıntıları zengin malzemeler sunmaktadır. Bu kalıntıların araştırılması sonucu ortaya çıkarılacak laboratuvar tetkikleri sayesinde Altın Orda'da yayılan "Kara Ölüm" detaylı bir şekilde kanıtlanabilecektir. Aynı zamanda Batı Avrupa'nın ve Bulgar şehrinin mezarlarında elde edilen bulguların analizinden itibaren bütün sonuçlar elde edilmiştir, fakat bu araştırma ekibinin uzmanları tarafından Türkistan'da ve Batı Avrupa'da Orta Çağ veba salgını dalgasının ve vebanın 19. yüzyılın sonunda ve 20. yüzyılın başında Uzak Doğu'da birkaç ülkede yayılmaya başlamasının hipotezi şiddetle reddedilmiş olmasına rağmen yeni bir tezin ortaya atılmasına engel teşkil etmemiştir. Çalışmanın en büyük dezavantajlarından biri tüm sonuçların yalnızca Orta Çağ vebasına neden olan virüs veya bakterilerin farklılıklarının incelenmesine dayanmasıdır. Araştırmacılar bu çalışmada yalnız tarihî verileri ihmâl etmekle kalmayıp, veba epidemolojisindeki verileri de ihmâl etmişlerdir.

14. yüzyılın ortalarında bilindiği gibi Altın Orda toprakları dâhil olmak üzere Avrasya'nın çoğu bölgeleri vebanın pençesinde kaldı. Hatta ticaret yollarının topluluklar arası etkileşimi sağlamaktaki işlevi dolayısıyla veba geniş bir coğrafyaya yayılarak birçok insanın ölümüne sebep oldu. Tam da bu dönemde, Altın Orda Devleti politik sıkıntılara, kendi içindeki problemlere odaklanmak mecburiyetindeydi. Buna paralel olarak devletin bir kriz yaşadığı, ekonomik ilişkilerin yıkıma uğradığı, devlet otoritesinin sarsılarak Cengiz Hanedanı'nın temellerinin sarsıldığı gözlemlenmiştir. Bu durum, Altın Orda'nın ticari alandan büyük ölçüde soyutlanmasına neden olmuştur; böylelikle Altın Orda'daki vebanın ticaret yoluyla daha geniş coğrafyalara da yayılmasına engel olmuştur. İnsan, tabiatta kendini daima muhafaza etmekle yükümlü olduğu gibi, salgınlar ve vebalara karşı da kendini muhafaza etme yöntemleri geliş̧irmiştir. Doğu Müslümanları salgın hastalıklara karşı sıklıkla hastalığın kaynaklandığı bölgeyi karantinaya almak işlemini uygulamışlardır. Ancak bunun dışında, istisnai olarak da kullanılan muhtelif yöntemler olmuştur. Örneğin; 1395-1396 yıllarında Timur'dan alınan yenilginin ardından halk, şehirleri restore etmek yerine başka bölgelerde yeni yerleşimler kurmayı tercih etmiştir. Kuça, bu şehirlerden biridir. ${ }^{4}$ Yine aynı önem içerisinde güvenli ve tehlikeden münezzeh bölgelere ulaşan boylar kendi egemenliklerini de meşrulaştırarak buralarda yeni yönetimler tesis etmişlerdi. Terk edilen bölgelerin civarları ise yaşamdan kopuk, birer harabe olarak kalmıştı. Sıkıntıların devam ettiği 1360 ve 1370 yılları arasında bu yeni şehirler için en önemlisi de Saray şehri için kendi aralarında büyük mücadeleler vermişlerdi. Timur’a karşı alınan yenilgi ve baş gösteren salgınlar nedeniyle 1398

\footnotetext{
${ }^{3}$ A. M. Spirou, R. I. Tukbatova, "Historical Y. Pestis Genomes Reveal the Europen Black Death as the Source of Ancient and Modern Plague Pandemics”, Cell Host and Microbe, 2016-2019, ss. 874-881. (Bu makalenin eleştirisi Timur Faritoviç tarafından yapılmıştır.)

${ }^{4}$ Mirgaleev, age, s. 142-143.
} 


\section{TOKTAMIŞ VE TIMUR'UN MÜCADELESİ ZAMANINDA VEBA}

yılına kadar Saray ve çevresi karantina bölgesi haline geldi. Timur'dan alınan yenilginin ardından muhtemelen vebadan kaynaklı olarak bu şehir için bir daha inşa faaliyetine girişilmedi. Kısaca diyebiliriz ki, veba Altın Orda'nın merkezî bölgelerindeki insanlara büyük sıkıntılar yaşattı.

Bilindiği üzere Timur ile Toktamış'ın arasındaki çekişme, ekonomik ve politik krizlerin şiddetlenmesine bağlı olarak gerçekleşmişti. ${ }^{5}$ Her zaman salgınlar ve veba, askerî seferlerle beraber geldi. Bununla birlikte mevcut salgından dolayı ciddi insan kaybı yaşanması tehlikesine rağmen iki taraf da kendi amacı için savaşmayı yeğledi. İşte Timur ve Toktamış'ın mücadeleleri de böyle bir akıbeti beraberinde getirdi. Anlatısal kaynaklardaki bilgilere dayanarak 1396 yılında Timur'un Altın Orda topraklarını aceleyle terk etmesi veba salgınıyla ilişkilendirildi.

Timur'un faal olan ordusu Cuci Ulusu'nun topraklarında uzun bir süre hareketsiz olarak kaldı. Bu durum Altın Orda şehirlerinin yıkımı gibi belirli görevleri icra etmenin yanı sıra mücadele edilecek ve savaşılacak birinin olduğu anlamına gelmektedir. Aceleyle ayrılma ise hayatta kalma arzusuyla bağlantılıdır. Timur'a doğrudan meydan okuyabilecek ve tehdit edebilecek güçlü bir ordu yoktu. Bundan dolayı Timur'un ordusunun geri çekilmesine dair yeterli değerlendirmeler Ortaçağ kaynaklarında bulunmaktadır. Rus vakayinamelerinde “Tanrı'nın kızgınlığı, hayvanlarda ve insanlarda vebaya neden olmuştu." denilerek, Timur'un Ordusu'nda ve iaşe için kullanılan hayvanlarda vebanın baş gösterdiği belirtilmiştir. ${ }^{6}$ Timur'un tarihçelerine göre ise ordusu zayıflamış ve ruhen bir düşüş yaşanmıştır. ${ }^{7}$ Bunun üzerine Timur, yeni bir emir vererek 1396 baharında ordusuyla elde ettiği ganimetler ve esirlerle Kafkaslar üzerinden İran'a gelmiştir.

Savaştan sonra 1395 baharında Toktamış, Bulgar civarlarında ağaçlık bir bölgeye kaçmıştır. ${ }^{8}$ Daha sonra 1395 ve 1396 kışında Altın Orda topraklarında kıtlık başlamış ve vebanın kaynağı da ortaya çıkmıştır. Bu olumsuz durumlar 1398 yılına kadar devam etmiş ve bu yılın sonunda yavaş yavaş azalmaya başlamıştır. Fakat veba tamamen 1405 yllında bitmiştir. ${ }^{9}$

Açıkça, veba salgını Aşağı İtil Bölgesi'nde bulunan birçok şehri harap etti. Bölgede yaşayan ahali göç ederek farklı bölgelerde yerleşim yerleri kurdu. Dönemin tanıklarından olan İbn Arabşah, insanların topluca bölgeleri terk ettiğini, farklı bölgelerde yerleşimler kurduklarını, hatta bir kesimin de Bizans ve Rus topraklarına doğru ayrıldığını belirtmiştir. ${ }^{10}$

Her şeyden önce kitlesel hastalıklar Altın Orda'nın içtimaî ve politik hayatını olumsuz tesir altında bırakmıştır. Altın Orda Devleti'nin sosyo-politik sistemindeki büyük yıkımların ve düşüşlerin artışına bakıldığında bu faktörün sistemi etkileyen belirleyici nedenler arasında olduğu görülmektedir.

\section{KAYNAKÇA}

LAVROV, L. İ., Epigrafiçeskiye Pamyatniki Severrnogo Kafkaza Na Arabskom, Persidskom i Turetskom Yazıkah, (Tesktı Perrkom Vvedeniye İ Prilojeniye) Hauka: Moskva 1966.

MIRGALEEV, İ. M., “Popitki Vozrojdeniya Zolotoy Ordı v Kontse XVI- Naçale XV v.”, Zolotoy Orda v Mirovoy Istorii, Kollektivnaya Monografiya, Kazan, 2016, s. 698-704.

MIRGALEEV, İ. M., “Toktamış i Timur: Restavratsiya Antimamlyukskoy Koalitsi,” 2. Materialı Vtoroy Mejdunarodnoy Nauçnoy Konferentsi "Politiçeskaya İ Sotsialnaya İstoriya Zolotoy Ordl, Posviyeşennaya Pamyati M.A. Usmanova, Kazan, 29-30 Marta, 2011, s. 27-32.

MIRGAleEV, İ. M., Politiçeskaya İstoriya Zolotoy Ordı Perioda Pravleniya Toktamış-Hana, Kazan: Almalit, 2003, s. 63-84.

\footnotetext{
${ }^{5}$ İ. M. Mirgaleev, "Popitki Vozrojdeniya Zolotoy Ordı v Kontse XVI- Naçale XV v.”, Zolotoy Orda v Mirovoy İstorii, Kollektivnaya Monografiya, Kazan, 2016, s. 698-704

${ }^{6}$ Patriarșaya İli Nikonskaya Letopis, M. Nauka, 1965

${ }^{7}$ V. G. Tizengauzen, Sbornik Materialov, Otnosyaşihsiya K İstorii Zolotoy Ordı. İzvleçeniye İz Soçineniy Arabskih, T. I. Spb: Tip-Ya İAN, SSCB, 1941, s. 564

${ }^{8}$ V. G. Tizengauzen, Sbornik Materialov, Otnosyaşihsiya K İstorii Zolotoy Ordl. İzvleçeniye İz Soçineniy Persidskiy, Sobrannıye, İzd-vo: AN SSSR, 1941, s. 308

${ }^{9}$ L. İ. Lavrov, Epigrafiçeskiye Pamyatniki Severrnogo Kafkaza Na Arabskom, Persidskom İ Turetskom Yazıkah, (Tesktı Perrkom Vvedeniye İ Prilojeniye) Hauka: Moskva, Moskva, 1966, s. 178.

${ }^{10}$ Tizengauzen, Sbornik Materialov, Otnosyaş̧ihsiya K İstorii Zolotoy Ordı. İzvleçeniye İz Soçineniy Arabsikih. s. 470.
} 


\section{ILNUR M. MIRGALEEV}

Patriarşaya İli Nikonskaya Letopis, M. Nauka, 1965.

SPIROU M., TUKBATOVA, R. I., "Historical Y. Pestis Genomes Reveal the Europen Black Death as the Source of Ancient and Modern Plague Pandemics”, Cell Host and Microbe, 2016-2019, pp. 874-881

TIZENGAUZEN, V. G., Sbornik Materialov, Otnosyaşihsiya K İstorii Zolotoy Ordı. İzvleçeniye İz Soçineniy Arabskih, T. I. Spb: Tip-Ya İAN, SSCB, 1941.

TIZENGAUZEN, V. G., Sbornik Materialov, Otnosyaşihsiya K İstorii Zolotoy Ord. İzvleçeniye İz Soçineniy Persidskiy, Sobranniye, İzd-vo: AN SSSR, 1941. 
TOKTAMIŞ VE TIMUR'UN MÜCADELESİ ZAMANINDA VEBA 